University of Wollongong

Research Online

Faculty of Engineering and Information

Faculty of Engineering and Information

Sciences - Papers: Part A

Sciences

$1-1-2016$

\title{
Enhanced mechanical properties of ARB-processed aluminum alloy 6061 sheets by subsequent asymmetric cryorolling and ageing
}

Hai Liang Yu

University of Wollongong, Central South University, hailiang@uow.edu.au

Lihong Su

University of Wollongong, lihongsu@uow.edu.au

Cheng Lu

University of Wollongong, chenglu@uow.edu.au

Anh Kiet Tieu

University of Wollongong, ktieu@uow.edu.au

Hui Jun Li

University of Wollongong, huijun@uow.edu.au

See next page for additional authors

Follow this and additional works at: https://ro.uow.edu.au/eispapers

Part of the Engineering Commons, and the Science and Technology Studies Commons

Research Online is the open access institutional repository for the University of Wollongong. For further information contact the UOW Library: research-pubs@uow.edu.au 


\title{
Enhanced mechanical properties of ARB-processed aluminum alloy 6061 sheets by subsequent asymmetric cryorolling and ageing
}

\begin{abstract}
Grain size and precipitations affect the strength and ductility of ultrafine-grained materials. In this study, aluminum alloy 6061 sheets were fabricated using the accumulative roll bonding (ARB) technique. The ARB-processed sheets were subsequently subjected to cryorolling and asymmetric cryorolling. The sheets were further aged at $100{ }^{\circ} \mathrm{C}$ for $48 \mathrm{~h}$. Mechanical tests show that a combination of asymmetric cryorolling and ageing results in significant improvement in both the ductility and the strength of the ARBprocessed sheets. The microstructures of the sheets at different stages of the process were also analyzed using optical microscopy, scanning electron microscopy, transmission electron microscopy and $\mathrm{X}$-ray diffraction in order to correlate the mechanical properties with the microstructure.
\end{abstract}

\section{Keywords}

sheets, processed, arb, 6061, properties, mechanical, alloy, subsequent, asymmetric, enhanced, cryorolling, ageing, aluminum

\section{Disciplines \\ Engineering | Science and Technology Studies}

\section{Publication Details}

Yu, H., Su, L., Lu, C., Tieu, K., Li, H., Li, J., Godbole, A. \& Kong, C. (2016). Enhanced mechanical properties of ARB-processed aluminum alloy 6061 sheets by subsequent asymmetric cryorolling and ageing. Materials Science and Engineering A: Structural Materials: Properties, Microstructure and Processing, 674 256-261.

\section{Authors}

Hai Liang Yu, Lihong Su, Cheng Lu, Anh Kiet Tieu, Hui Jun Li, Jintao Li, Ajit R. Godbole, and Charlie Kong 


\section{Enhanced mechanical properties of ARB-processed aluminum alloy 6061 sheets by subsequent asymmetric cryorolling and ageing}

Hailiang $\mathrm{YU}^{1,2^{*}}$, Lihong $\mathrm{SU}^{2}$, Cheng $\mathrm{LU}^{2}$, Kiet $\mathrm{TIEU}^{2}$, Huijun $\mathrm{LI}^{2, *}$, Jintao $\mathrm{LI}^{2}$, Ajit $\mathrm{GODBOLE}^{2}$, Charlie $\mathrm{KONG}^{3}$

${ }^{1}$ State Key Laboratory of High Performance Complex Manufacturing, Central South University, Changsha 410083, China. ${ }^{2}$ School of Mechanical, Materials \& Mechatronics Engineering, University of Wollongong, NSW 2500, Australia. ${ }^{3}$ Electron Microscope Unit, University of New South Wales, Sydney, NSW 2052, Australia.

Abstract: Grain size and precipitations affect the strength and ductility of ultrafine-grained materials. In this study, aluminum alloy 6061 sheets were fabricated using the accumulative roll bonding (ARB) technique. The ARB-processed sheets were subsequently subjected to cryorolling and asymmetric cryorolling. The sheets were further aged at $100^{\circ} \mathrm{C}$ for 48 hours. Mechanical tests show that a combination of asymmetric cryorolling and ageing results in significant improvement in both the ductility and the strength of the ARB-processed sheets. The microstructures of the sheets at different stages of the process were also analyzed using optical microscopy, scanning electron microscopy, transmission electron microscopy and X-ray diffraction in order to correlate the mechanical properties with the microstructure.

Keywords: Aluminum alloy 6061 sheet; accumulative roll bonding; asymmetric cryorolling; ageing; mechanical properties

\section{Introduction}

High strength and high ductility of ultrafine-grained (UFG) materials have attracted increasing attention in recent times [1-3]. A number of severe plastic deformation (SPD) techniques have been developed to fabricate bulk UFG materials. The most

\footnotetext{
*Corresponding author: YU H.L., email: hailiang@uow.edu.au, yuhailiang1980@tom.com; LI H.J., email: huijun@uow.edu.au
} 
widely used techniques include equal channel angular pressing (ECAP) [4, 5], high pressure torsion (HPT) [6,7], accumulative roll bonding (ARB) [8-10], asymmetric rolling (AR) $[11,12]$ and cryorolling (CR) $[13,14]$. Among these techniques, ARB, $\mathrm{AR}$ and $\mathrm{CR}$ can be applied to produce UFG sheets. Asymmetric cryorolling (ACR) [15] is a technique that combines features of AR and CR, and is used to develop UFG materials. ACR is characterized by an additional shear deformation in the rolling deformation zone, compared to CR.

Deformation at cryogenic temperature is one of the main mechanisms leading to improvement in both strength and ductility of UFG materials as well as (i) narrow grain size distribution, (ii) bi-modal structure, (iii) gradient structure, (iv) nanotwinned structure, (v) transformation-induced enhancement of ductility, (vi) tailoring of the stacking fault energy via alloying and (vii) precipitation-hardened alloy [3]. The higher strength of samples subjected to cryogenic deformation is seen to result from grain refinement and suppression of dynamic recovery. On the other hand, the higher ductility of samples subjected to cryogenic deformation is attributed to the change in (i) the fraction of high-angle boundaries, (ii) the density of pre-existing deformation twins [16] and (iii) the density of dislocations [17]. Shi et al [17] found that dislocations in some special configurations are movable, which prevents localized shear deformation and contributes to the improved ductility of CR-processed Zr. Recently, Yu et al [18] found that simultaneous grain growth and grain refinement appear in $\mathrm{CR}$-processed UFG $\mathrm{Cu}$ sheets, which results in a high-true failure strain of 1.5. A number of studies on CR-processed UFG Al have reported good ductility of the materials [19-21]. Immanuel and Panigrahi [19] found that CR resulted in break up and uniform distribution of coarse acicular eutectic particles in the Al matrix, elimination of casting porosity, microstructural refinement and significant accumulation of dislocation density. This resulted in great improvement in the strength $(248 \%)$ and the ductility $(37 \%)$ of a cast Al-Si alloy. There have been some investigations which show that additional processing of the specimens produced using the above techniques can further improve the mechanical properties of UFG 
metals. Biswas et al [22] studied the effect of subsequent rolling on the microstructure and texture of ECAP-processed pure Mg. The grain size of the samples after ECAP was reduced to $12 \sim 18 \mu \mathrm{m}$, and subsequent rolling led to a mean grain size $8 \sim 10 \mu \mathrm{m}$ with the basal texture fiber parallel to the normal direction. Hajizadeh and Eghbali [23] studied the microstructure and mechanical properties of ECAP-processed commercial pure Ti during subsequent $\mathrm{CR}$ with a $35 \%$ reduction in thickness. After 10 passes of ECAP, a UFG structure with average grain size of $213 \mathrm{~nm}$ was achieved with mainly equiaxed grains. Subsequent CR led to further refinement and decreased the grain size to $114 \mathrm{~nm}$ with lamellar structure and higher dislocation density. Ma et al [24] used HPT followed by rolling to develop high strain hardening and ductility in coarse-grain/nanostructure laminate materials. Yu et al $[25,26]$ found that both the ductility and the strength of ARB-processed pure aluminum foils could be improved by subsequent AR. The effect of subsequent cold rolling on the thermal stability of ARB-processed Al-Fe-Mn-Si foils was investigated by Homola et al [27]. They found that the samples subjected to ARB followed by cold rolling went through continuous recrystallization. Yu et al [28] studied the evolution of the microstructure and the mechanical properties of ARB-processed pure Al sheets subjected to CR. The mean grain size of $460 \mathrm{~nm}$ after the third ARB pass could be reduced to $290 \mathrm{~nm}$ after two CR passes, amounting to a total reduction of $80 \%$. However, to the best of the authors' knowledge, there have been no reports on the effect on the microstructure evolution of UFG materials subjected to subsequent ACR and ageing.

Aluminum alloy 6061 (AA6061) is one of the most important precipitation-hardenable Al-Mg-Si alloys. This alloy has many desirable properties such as medium strength, formability, weldability, corrosion resistance and low cost compared to other Al alloys [29, 30]. Previous research [8-10] has shown that ARB-processed AA6061 sheets have excellent mechanical properties. In the present study, ARB-processed AA6061 sheets were subjected to subsequent CR and ACR separately. Both were then aged at $100^{\circ} \mathrm{C}$ for $48 \mathrm{~h}$. The mechanical properties and microstructure evolution of the sheets were analyzed. 


\section{Experimental Investigation}

In this study, commercial AA6061 sheets of thickness $1.5 \mathrm{~mm}$ were used. Before rolling, the sheets were fully annealed. Fig. 1 shows a schematic diagram of rolling processes. The sheets were first subjected to five ARB passes in succession. The thickness of the ARB-processed sheets was further reduced to $0.5 \mathrm{~mm}$ by $\mathrm{CR}$ and ACR separately on a multifunction roll mill having $50 \mathrm{~mm}$ diameter work rolls. Before $\mathrm{CR}$ and $\mathrm{ACR}$, the ARB-processed sheets were cooled by liquid nitrogen for 10 min. The ratio (upper roll rolling speed/ lower roll rolling speed) was 1.0 for CR and 1.4 for ACR. Finally, the (ARB + CR) - processed and (ARB + ACR) - processed sheets were aged at $100^{\circ} \mathrm{C}$ for 48 hours, which was chosen to achieve excellent mechanical properties $[29,30]$. After ARB, some edge cracks were observed in the AA6061 sheets. These edge cracks were trimmed before CR/ACR processing, and were not observed to reappear during the $\mathrm{CR} / \mathrm{ACR}$ processing.

Fig. 1. Schematic diagram of sheet rolling processes. Step 1: Five ARB passes; Step 2: Reduction of the thickness of sheets to $0.5 \mathrm{~mm}$ using CR or ACR

The engineering stress-strain curves of the samples after annealing, ARB, (ARB + $\mathrm{CR}),(\mathrm{ARB}+\mathrm{CR}+$ ageing $),(\mathrm{ARB}+\mathrm{ACR})$ and $(\mathrm{ARB}+\mathrm{ACR}+$ ageing $)$ were obtained using an INSTRON machine with an initial strain rate of $1.0 \times 10^{-3} \mathrm{~s}^{-1}$. The micro-hardness of the samples was measured with a Vickers hardness tester using a load of $5 \mathrm{~g}$ and a dwell time of $12 \mathrm{~s}$. The fracture surface of the samples after the tensile test was observed using a high- performance field emission scanning electron microscope (FESEM) on a Carl Zeiss AURIGA workstation. The microstructure of the fully annealed sample was inspected using optical microscopy. The microstructures of the samples subjected to $\mathrm{ARB},(\mathrm{ARB}+\mathrm{CR}),(\mathrm{ARB}+\mathrm{CR}+$ ageing), $(\mathrm{ARB}+\mathrm{ACR})$ and $(\mathrm{ARB}+\mathrm{ACR}+$ ageing) were investigated using a transmission electron microscope (TEM). The TEM images were obtained in transverse direction (TD), in the plane of rolling direction (RD) and the normal direction (ND). A GBC MMA X-ray diffractometer (XRD) with $\mathrm{Cu} \mathrm{K \alpha}$ radiation $(\lambda=1.5418 \AA$ ) was used to measure the phase diffraction profiles of the samples after $(A R B+C R),(A R B+C R$ 
+ ageing), $(\mathrm{ARB}+\mathrm{ACR})$ and $(\mathrm{ARB}+\mathrm{ACR}+$ ageing $)$.

\section{Results}

Fig. 2(a) shows the engineering stress-strain curves of the samples after annealing, $\mathrm{ARB},(\mathrm{ARB}+\mathrm{CR}),(\mathrm{ARB}+\mathrm{CR}+$ ageing), $(\mathrm{ARB}+\mathrm{ACR})$, and $(\mathrm{ARB}+\mathrm{ACR}+$ ageing) respectively. Compared to the 'annealed-only' sheet, the strength of the ARB-processed sheet was increased to $380 \mathrm{MPa}$, which was further increased to 437 MPa after CR and $454 \mathrm{MPa}$ after ACR. The subsequent ageing resulted in a slight increase in the tensile strength for the rolled sheets. Fig. 2(b) shows the micro-hardness of the samples after different processes. For the annealed sample, the micro-hardness is only 39, which increases to 94 after ARB processing. After subsequent CR and ageing processes, the micro-hardness was increased to 108 and 116 respectively. When subjected to subsequent ACR and ageing, the micro-hardness increased to 111 and 119 , respectively.

Fig. 2. (a) Engineering stress-strain curves and (b) micro-hardness of samples after different processes.

From Fig. 2(a), it can be seen that the ductility of the sheets increases after (ARB + $\mathrm{CR}),(\mathrm{ARB}+\mathrm{CR}+$ ageing), (ARB + ACR), and (ARB + ACR + ageing), compared to the ductility of the sheets after ARB only. The sheets after (ARB + ACR + ageing) have the maximum ductility. Fig. 3 shows the SEM images of the fracture surfaces of the samples after the tensile tests. For the $(A R B+C R)$ - processed samples, the fracture surface is smooth and there are only few large dimples. After (ARB + CR + ageing), the number of large dimples increases, implying that the ductility of sheets increases, as also shown in Fig. 2(a). For the samples subjected to (ARB + ACR) and ( $\mathrm{ARB}+\mathrm{ACR}+$ ageing), the change in the ductility is similar to that after $(\mathrm{ARB}+\mathrm{CR})$ and (ARB $+\mathrm{CR}+$ ageing). As shown in Fig. 3(d), the number of large dimples is much more than in the samples shown in Fig. 3(a) to Fig. 3(c). This implies that the sheets after (ARB + ACR + ageing) have the maximum ductility. The dimples shown in Fig. 3(d) are also much deeper, which results in further elongation after necking, as 
can be seen from the (ARB + ACR + ageing) curve in Fig. 2, compared to the immediate fracture after necking of the other three samples. Thus, from Figures 2 and 3 , it is seen that a combination of ACR and ageing technique can enhance both the strength and the ductility of ARB-processed AA6061 sheets.

Fig. 3. SEM images of fracture surface of samples after tensile tests: (a) (ARB + CR); (b) (ARB + CR + Ageing); (c) (ARB + ACR); (d) (ARB + ACR + Ageing).

Fig. 4 shows the microstructure of samples after the different processes. In Fig. 4(a), the annealed sample shows coarse equiaxed grains with a mean grain size of $\sim 38 \mu \mathrm{m}$. After ARB processing, the microstructure morphed into that of a UFG laminate structure, as shown in Fig. 4(b). With subsequent CR processing, the grain width was further refined to $175 \mathrm{~nm}$ (Fig. 4(c)), and the ageing results in a slight increase to 177 nm, (Fig. 4(d)). Following ACR processing of the ARB-processed sheets, the grain width was refined to $158 \mathrm{~nm}$ (Fig. 4(e)), and the ageing leads to a slight increase to $161 \mathrm{~nm}$, (Fig. 4(f)). Compared to the (ARB + CR) - processed sheets, the grain size is smaller for the sheets processed by $(\mathrm{ARB}+\mathrm{ACR})$. Generally, with a decrease in grain size for UFG materials, the material strength increases. This agrees well with the results shown in Fig. 2. In addition, the grain size changes very slightly for the samples after ageing at $100^{\circ} \mathrm{C}$ for 48 hours. This suggests that the microstructures of UFG sheets processed by $(\mathrm{ARB}+\mathrm{CR})$ and $(\mathrm{ARB}+\mathrm{ACR})$ are thermally stable at temperatures $\leq 100^{\circ} \mathrm{C}$.

Fig. 4. (a) Optical microscope image of sheet before rolling; (b) TEM image of sample after the fifth ARB pass; TEM images and related grain size distribution (100 grains) after (c) (ARB + CR), (d) (ARB + CR + ageing), (e) (ARB + ACR) and (f) (ARB + ACR + ageing).

Fig. 5 shows the XRD results after the different processes. As highlighted in Fig. 5, compared to $(\mathrm{ARB}+\mathrm{CR})$, the fraction of $\mathrm{Mg}_{2} \mathrm{Si}$ and $\mathrm{CuAl}_{2}$ precipitates increases slightly after (ARB $+\mathrm{CR}+$ ageing). This may result in a slight increase in the strength and ductility of the sheets. However, for the samples after (ARB + ACR + ageing), it is obvious that the precipitations of $\mathrm{Mg}_{2} \mathrm{Si}$ and $\mathrm{CuAl}_{2}$ and $\mathrm{Al}_{6} \mathrm{Mn}$ increase 
significantly compared to the samples after (ARB + ACR). Previous studies have shown that the precipitations in AA6061 alloy increase the ductility and strength of the sheets $[23,24]$. This finding agrees well with the present study, as seen in Fig. 2.

Fig. 5. XRD results for AA6061 sheets after (a) (ARB + CR), (b) (ARB + CR + ageing), (c) (ARB + ACR) and (d) (ARB + ACR + ageing).

\section{Discussion}

Grain size and precipitation(s) affect the mechanical properties of UFG materials. As shown in Fig. 2, the UFG AA6061 sheets subjected to (ARB + ACR + ageing) show the highest strength and ductility compared to sheets processed differently. According to the Hall-Petch equation [31], the strength increases as the grain size reduces. In this study, the grain size of the samples after (ARB+ACR) is smallest compared to those after other processes, as shown in Fig. 4. Generally, the strength and the ductility of UFG materials are conflicting properties [32]: ductility of materials will generally reduce with higher strength. However, it is difficult to explain the increase in ductility after (ARB + ACR + ageing). Simultaneous improvement in both strength and ductility is possible in UFG materials with (1) bimodal structure [26, 33], (2) nanotwinned structure [34], (3) deformed at cryogenic temperatures [14, 16], and (4) precipitation-hardened alloy $[30,35]$. In the present study, we believe that that the precipitation (Fig. 5) and cryogenic deformation are the main contributions for enhancing the mechanical properties of UFG AA6061 sheets.

Fig. 5 shows that the density of precipitation of the sample after (ARB + ACR + ageing) is higher than that after (ARB $+\mathrm{CR}+$ ageing). The newly formed precipitation will contribute to the improvement of ductility and strength. Fig. 3(d) shows some traces of precipitations in the deeper dimples. Previous research indicates that ageing of an SPD-processed AA6061 at $100^{\circ} \mathrm{C}$ for 48 hours can lead to improvement in the mechanical properties $[9,36]$. Rezaei et al [9] found that the micro-hardness of the ARB-processed AA6061 sheets increased as the ageing time 
increased from 0 to 48 hours at $100^{\circ} \mathrm{C}$, while it reduced with further increase in the ageing duration to 56 hours. Kim et al [36] studied the microstructural evolution during ageing of ECAP-processed AA6061 at temperatures from $100^{\circ} \mathrm{C}$ to $600^{\circ} \mathrm{C}$, and found that ageing at $100^{\circ} \mathrm{C}$ resulted in the best combination of mechanical properties. There are many investigations on precipitations of AA6061 during ageing [37]. For samples without plastic deformation, the precipitations occur in the following sequence: (1) Al super-saturated solid solution (SSSS) $\rightarrow$ (2) Clusters of Si atoms and

$\mathrm{Mg}$ atoms $\rightarrow(3)$ Dissolution of Mg clusters $\rightarrow$ (4) Formation of $\mathrm{Mg} / \mathrm{Si}$ co-clusters $\rightarrow$ (5) small precipitates of unknown structure $\rightarrow$ (6) $\beta^{\prime \prime}$ precipitates $\rightarrow$ (7) $\beta^{\prime} / \mathrm{B}^{\prime}$ precipitates $\rightarrow$ (8) $\beta-\mathrm{Mg}_{2} \mathrm{Si}$ precipitates [37]. For plastically deformed samples, it is easier for the precipitates to nucleate and grow on dislocation lines [38]. Compared to $\mathrm{CR}$, there is an additional shear strain on the sheets during ACR, which results in a higher dislocation density in the sheets. Thus, ageing of (ARB + ACR)-processed sheets results in more precipitations in AA6061 sheets. It can be seen in Fig. 5 that the fraction of $\mathrm{Mg}_{2} \mathrm{Si}$ precipitates in the sheets is the highest after (ARB $+\mathrm{ACR}+$ Ageing). In addition, during ageing, with an increase in the density of precipitates, a significant number of dislocations are annihilated, which improves the ductility of the aged samples. Panigrahi et al [39, 40] studied the mechanical properties and microstructure of AA6063 after a combined treatment of CR, short-annealing and ageing. They found that dislocation accumulation and nanosized precipitates are responsible for enhancing the strength, while nanosized precipitates and a low dislocation density improve the ductility of the CR-processed AA6063 subjected to an optimized treatment of short-duration annealing and ageing.

\section{Conclusions}

(1) Both cryorolling (CR) and asymmetric cryorolling (ACR) can result in enhanced strength and ductility of AA6061 sheets fabricated using accumulative roll bonding (ARB). The improvement in the mechanical properties following ACR is higher than that following CR. The strengths of AA6061 sheets fabricated using ARB, 
$(\mathrm{ARB}+\mathrm{CR})$ and $(\mathrm{ARB}+\mathrm{ACR})$ are $380 \mathrm{MPa}, 437 \mathrm{MPa}$ and $454 \mathrm{MPa}$, respectively.

(2) ARB-processed AA6061 sheets subsequently subjected to ACR and ageing at $100^{\circ} \mathrm{C}$ for 48 hours show the best mechanical properties due to finer grain size and higher density of precipitations.

(3) The higher density of precipitations for the aged (ARB + ACR) - processed sheets is due to the higher dislocation density induced by the additional shear strain during ACR, compared to (ARB + CR) - processed sheets.

\section{Acknowledgements}

This research was supported by URC small grant at the University of Wollongong and the Open Research Fund of the Key Laboratory of High Performance Complex Manufacturing, Central South University, China.

\section{References}

[1] Vinogradov A. Mechanical properties of ultrafine-grained metals: new challenges and perspectives. Advanced Engineering Materials, 2015, 17: 1710-1722.

[2] Huang Y., Langdon T.G. Advances in ultrafine-grained materials. Materials Today, 2013, 16: 85-93.

[3] Ocid'Ko I.A., Langdon T.G. Enhanced ductility of nanocrystalline and ultrafine-grained metals. Reviews on Advanced Materials Science, 2012, 30: $103-111$

[4] Valiev R.Z., Langdon T.G., Principles of equal-channel angular pressing as a processing tool for grain refinement. Progress in Materials Science, 2006, 51: 881-981.

[5] Angew S.R., Horton J.A., Lillo T.M., Brown D.W. Enhanced ductility in strongly textured magnesium produced by equal channel angular processing. Scripta Materialia, 2004, 50, 377-381. 
[6] Edalati K., Horita Z. A review on high-pressure torsion (HPT) from 1935-1988. Materials Science and Engineering A, 2016, 652: 325-352.

[7] Zhilyaev A.P., Langdon T.G. Using high-pressure torsion for metal processing: Fundamentals and applications. Progress in Materials Science, 2008, 53: 893-979.

[8] Lee S.H., Saito Y., Sakai T., Utsunomiya H. Microstructures and mechanical properties of 6061 aluminum alloy processed by accumulative roll-bonding. Materials Science and Engineering A, 2002, 325: 228-235.

[9] Rezaei M.R., Toroghinejad M.R., Ashrafizadeh F. Effects of ARB and ageing processes on mechanical properties and microstructure of 6061 aluminum alloy. Journal of Materials Processing Technology, 2011, 211: 1184-1190.

[10] Su L., Lu C., Gazder A.A., Saleh A.A., Deng G., Tieu K., Li H. Shear texture gradient in AA6061 aluminum alloy processed by accumulative roll bonding with high roll roughness. Journal of Alloys and Compounds, 2014, 594: 12-22.

[11] Kim K.H., Lee D.N. Analysis of deformation textures of asymmetrically rolled aluminum sheets. Acta Materialia, 2001, 49: 2583-2595.

[12] Yu H.L., Lu C., Tieu K., Li H.J., Godbole A., Zhang S.H. Special rolling techniques for improvement of mechanical properties of ultrafine-grained metal sheets: a review. Advanced Engineering Materials, 2016, 18: 754-769.

[13] Lee Y.B., Shin D.H., Park K.T., Nam W.J. Effect of annealing temperature on microstructures and mechanical properties of a $5083 \mathrm{Al}$ alloy deformed at cryogenic temperature. Scripta Materialia, 2004, 51: 355-359.

[14] Yu H.L., Tieu K., Lu C., Liu X., Liu M., Godbole A., Kong C., Qin Q.H. A new insight into ductile fracture of ultrafine-grained Al-Mg alloys. Scientific Reports, 2015, 5: 9568 .

[15] Yu H.L., Lu C., Tieu K., Liu X.H., Sun Y., Yu Q.B., Kong C. Asymmetric cryorolling for fabrication of nanostructural aluminum sheets. Scientific Reports, 2012, 2: 772 .

[16] Zhao Y.H., Bingert J.F., Liao X.Z., Cui B.Z., Han K., Sergueeva A.V., Mukherjee A.K., Valiev R.Z., Langdon T.G., Zhu Y.T. Simultaneously increasing the 
ductility and strength of ultra-fine-grained pure copper. Advanced Materials, 2006, 18: 2949-2953.

[17] Shi Y., li M., Guo D., Ma T., Zhang Z., Li X., Zhang G., Zhang X. Extraordinary toughening by cryorolling in Zr. Advanced Engineering Materials, 2014, 16: 167-170.

[18] Yu H.L., Lu C., Tieu A.K., Li H.J., Godbole A., Kong C., Zhao X. Simultaneous grain growth and grain refinement in bulk ultrafine-grained copper under tensile deformation at room temperature. Metallurgical and Materials Transactions A, 2016, 47: 3785-3789.

[19] Immanuel R.J., Panigrahi S.K. Influence of cryorolling on microstructure and mechanical properties of a cast hypoeutectic Al-Si alloy. Materials Science and Engineering A, 2015, 640: 424-435.

[20] Rangaraju N., Raghuram T., Vamsi Krishna B., Prasad Rao K., Venugopal P. Effect of cryo-rolling and annealing on microstructure and properties of commercially pure aluminium. Materials Science and Engineering A, 2005, 398: $246-251$

[21] Ranigrahi S., Jayaganthan R. Development of ultrafine grained Al-Mg-Si alloy with enhanced strength and ductility. Journal of Alloys and Compounds, 2009, 470: $285-288$.

[22] Biswas S., Singh D.S., Beausir B., Toth L.S., Suwas S. Thermal response on the microstructure and texture of ECAP and cold-rolled pure magnesium. Metallurgical and Materials Transactions A, 2015, 46: 2598-2613.

[23] Hajizadeh K., Eghbali B.Effect of two-step severe plastic deformation on the microstructure and mechanical properties of commercial purity titanium. Metals and Materials International. 2014, 20: 343-350.

[24] Ma X.L., Huang C.X., Xu W.Z., Zhou H., Wu X.L., Zhu Y.T. Strain hardening and ductility in a coarse-grain/nanostructure laminate material. Scripta Materialia, 2015, 103: 57-60.

[25] Yu H.L., Lu C., Tieu K., Godbole A., Su L., Sun Y., Liu M., Tang D., Kong C. Fabrication of ultra-thin nanostructured bimetallic foils by accumulative roll 
bonding and asymmetric rolling. Scientific Reports, 2013, 3: 2373.

[26] Yu H.L., Tieu K., Hadi S., Lu C., Godbole A., Kong C. High strength and ductility of ultrathin laminate foils using accumulative roll bonding and asymmetric rolling. Metallurgical and Materials Transactions A, 2015, 46: 869-879.

[27] Homola P., Slamova M., Slama P., Cieslar M. Thermal stability of ultrafine grains in Al-Fe-Mn-Si foils prepared by ARB and subsequent rolling. Materials Science Forum, 2008, 584-586: 905-910.

[28] Yu H.L., Wang H., Lu C., Tieu K., Li H.J., Godbole A., Liu X., Kong C., Zhao X. Microstructure evolution of accumulative roll bonding processed pure aluminium during cryorolling. Journal of Materials Research, 2016, 31: 797-805.

[29] Mohamed I.F., Lee S., Edalati K., Horita Z., Hirosawa S., Matsuda K., Terada D. Aging behavior of Al 6061 alloy processed by high-pressure torsion and subsequent aging. Metallurgical and Materials Transactions A, 2015, 46: 2664-2673.

[30] Yu H.L., Tieu K., Lu C., Liu X.H., Godbole A., Kong C. Mechanical properties of Al-Mg-Si alloy sheets produced using asymmetric cryorolling and ageing treatment. Materials Science and Engineering A, 2013, 568: 212-218.

[31] Hansen N. Hall-Petch relation and boundary strengthening, Scripta Materialia, 2004, 51: 801-806.

[32] Ritchie R.O. The conflicts between strength and toughness, Nature Materials, 2011, 10: 817-822.

[33] Wang Y., Chen M., Zhou F., Ma E. High tensile ductility in a nanostructured metal. Nature, 2002, 419: 912-915.

[34] Shen Y.F., Lu L., Lu Q.H., Jin Z.H., Lu K. Tensile properties of copper with nano-scale twins. Scripta Materialia, 2005, 52: 989-994.

[35] Xing L.Q., Eckert J., Löser W., Schultz L. High-strength materials produced by precipitation of icosahedral quasicrystals in bulk $\mathrm{Zr}$-Ti-Cu-Ni-Al amorphous alloys. Applied Physics Letters, 1999, 74: 664-666.

[36] Kim W.J., Wang J.Y. Microstructure of the post-ECAP aging processed $6061 \mathrm{Al}$ 
alloys. Materials Science and Engineering A, 2007, 464: 23-27.

[37] Edwards G.A., Stiller K., Dunlop G.L., Couper M.J. The precipitation sequence in Al-Mg-Si alloys. Acta Materialia, 1998, 46: 3893-3904.

[38] Teichmann K., Marioara C.D., Andersen S.J., Pedersen K.O., Gulbrandsen-Dahl S., Kolar M., Holmestad R., Marthinsen K. HRTEM study of the effect of deformation on the early precipitation behaviour in an AA6060 Al-Mg-Si alloy. Philosophical Magazine, 2011, 91: 3744-3754.

[39] Panigrahi S.K., Jayaganthan R. A study on the combined treatment of cryorolling, short-annealing, and aging for the development of ultrafine-grained Al 6063 alloy with enhanced strength and ductility. Metallurgical and Materials Transactions A, 2010, 41: 2675-2690.

[40] Panigrahi S.K., Jayaganthan R. Effect of annealing on precipitation, microstructural stability, and mechanical properties of cryorolled Al 6063. Journal of Materials Science, 2010, 45: 5624-5636. 


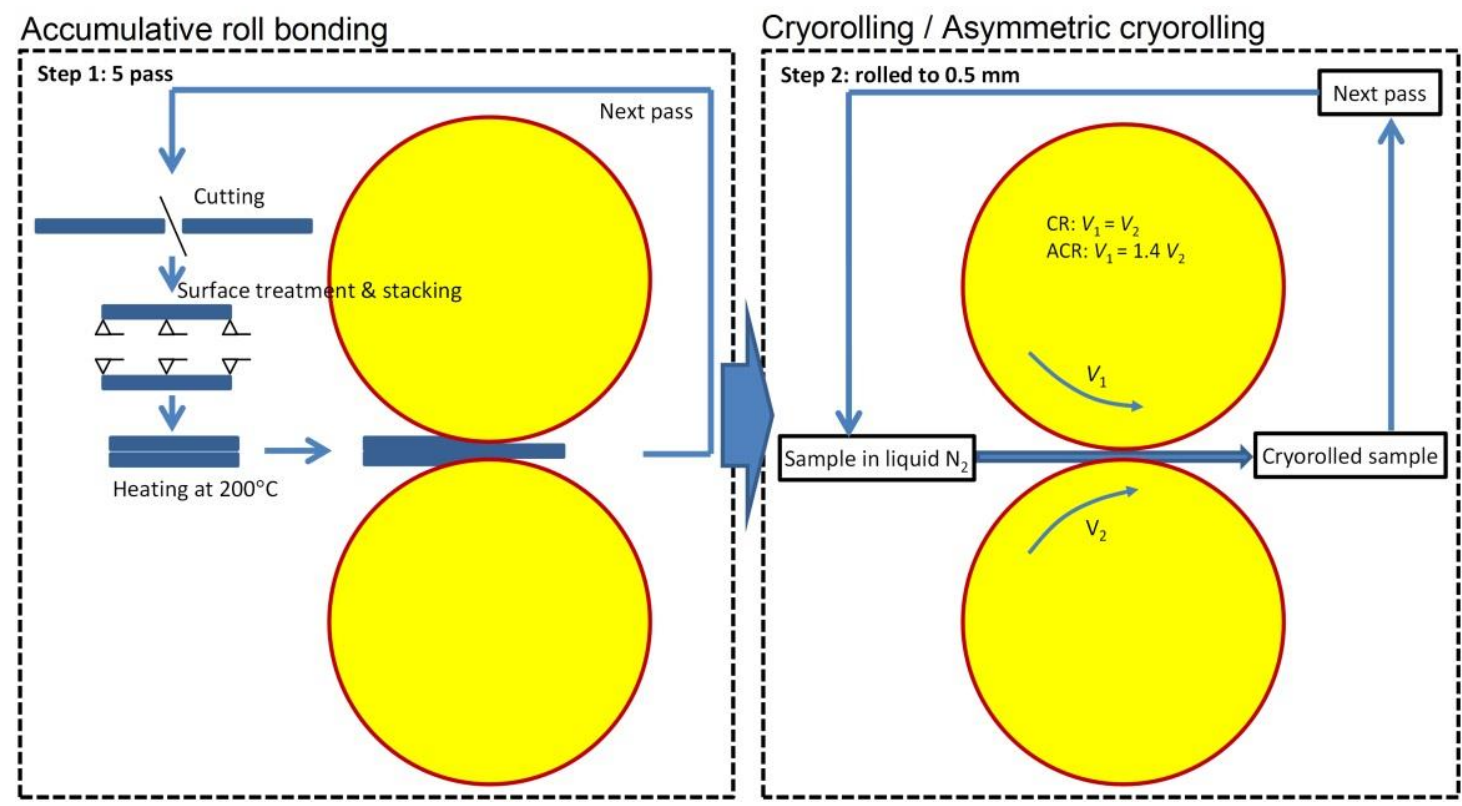

Fig. 1. Schematic diagram of sheet rolling processes. Step 1: Five ARB passes; Step 2: Reduction of the thickness of sheets to $0.5 \mathrm{~mm}$ using CR or ACR 

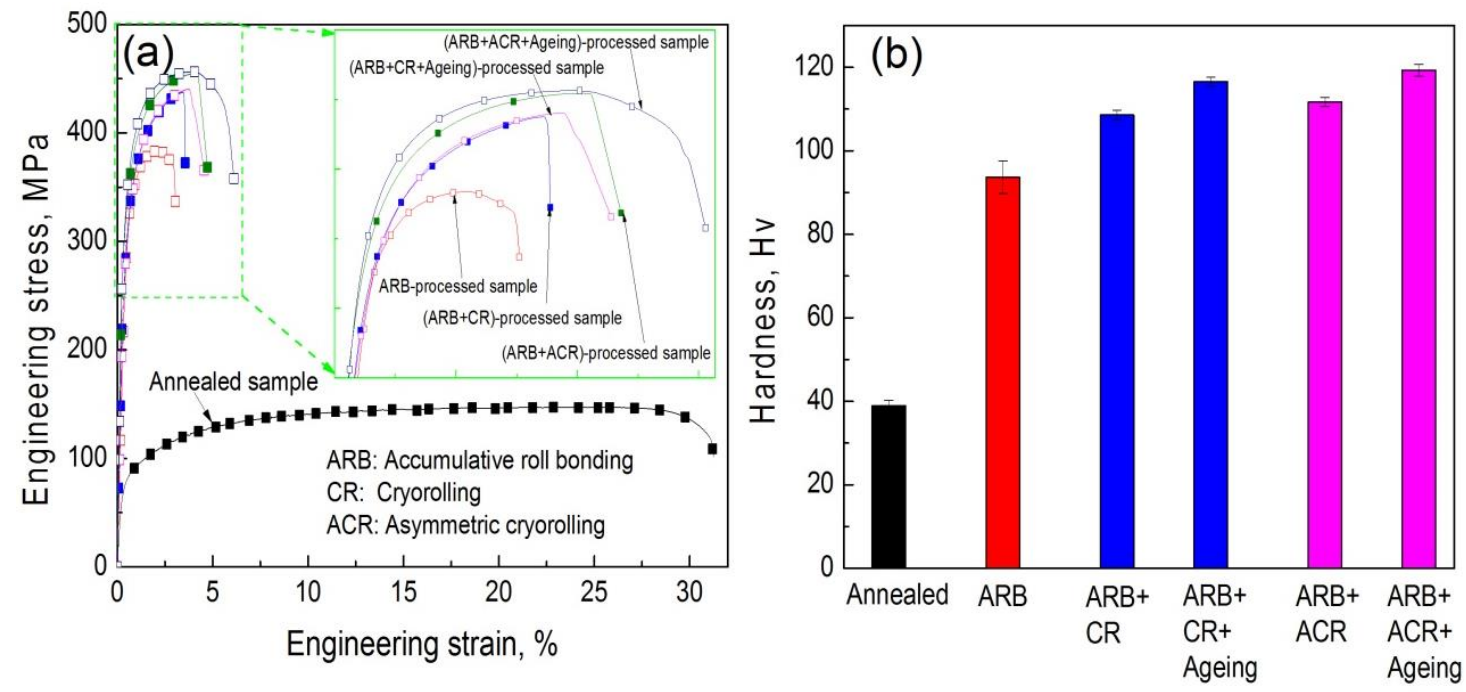

Fig. 2. (a) Engineering stress-strain curves and (b) micro-hardness of samples after different processes. 
(a)

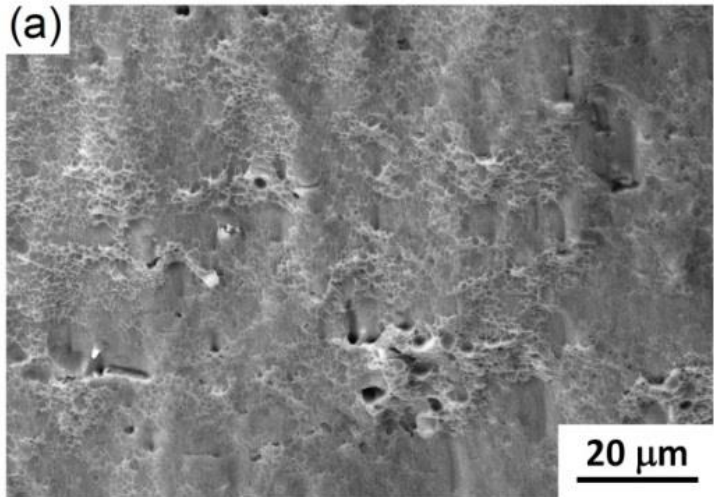

(c)

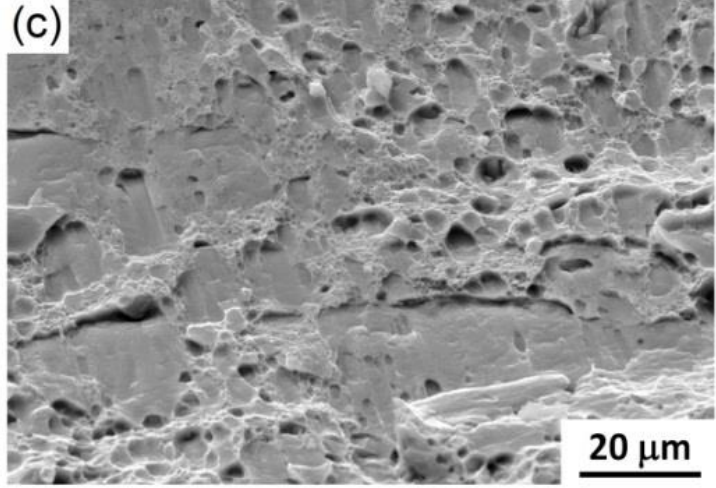

(b)

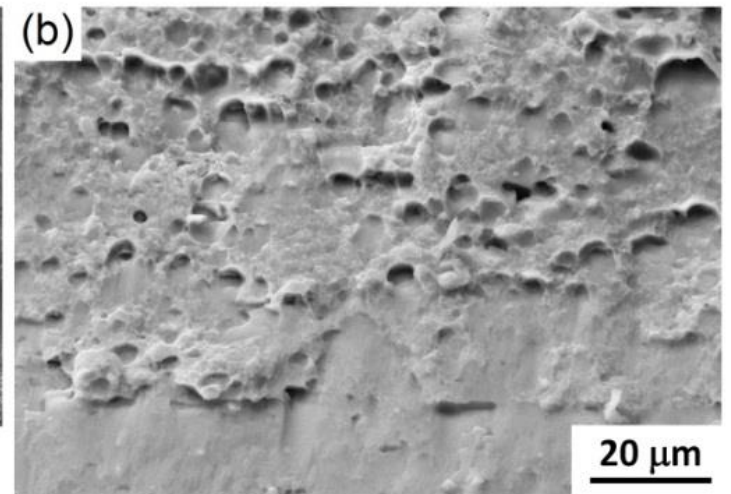

(d)

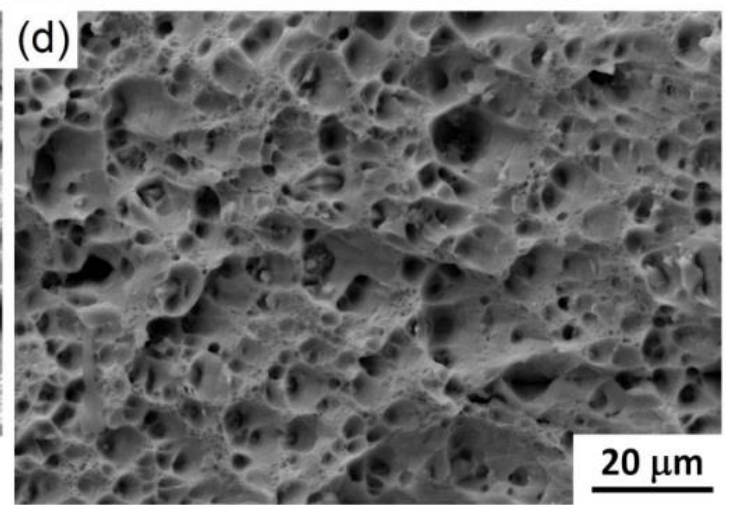

Fig. 3. SEM images of fracture surface of samples after tensile tests: (a) (ARB + CR); (b) (ARB + CR + Ageing); (c) (ARB + ACR); (d) (ARB + ACR + Ageing). 

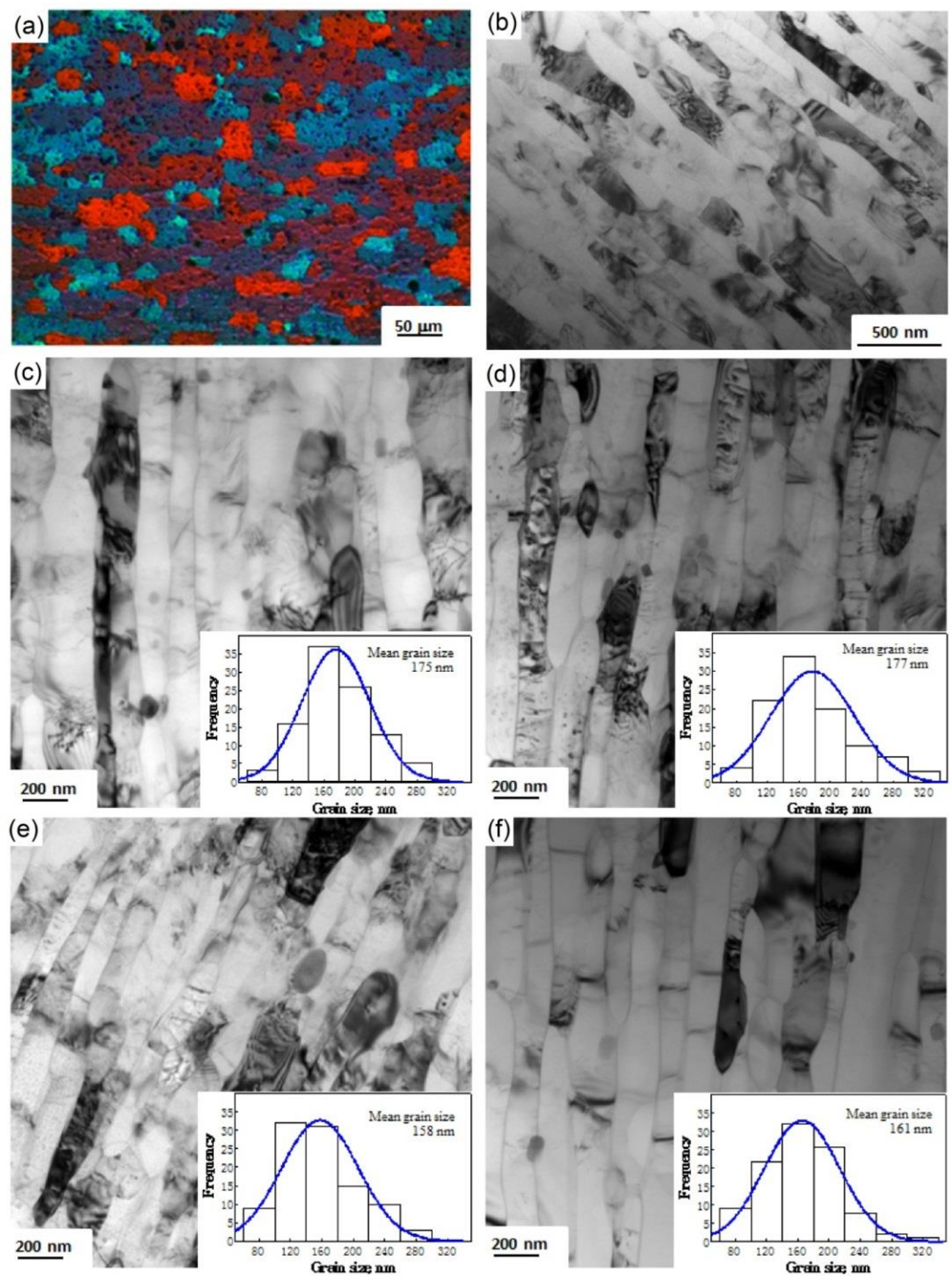

Fig. 4. (a) Optical microscope image of sheet before rolling; (b) TEM image of sample after the fifth ARB pass; TEM images and related grain size distribution (100 grains) after (c) (ARB + CR), (d) (ARB + CR + ageing), (e) (ARB + ACR) and (f) (ARB + ACR + ageing). 


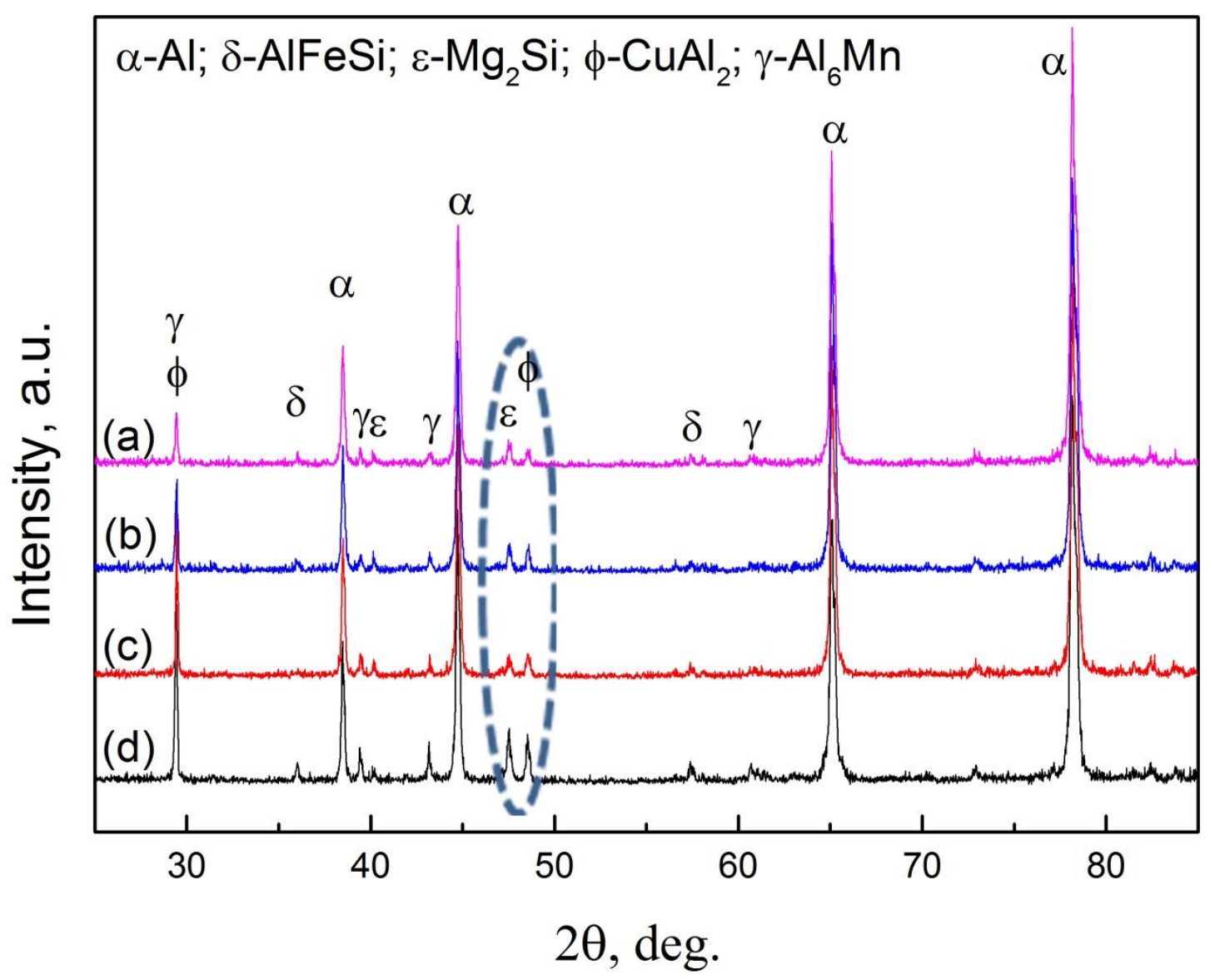

Fig. 5. XRD results for AA6061 sheets after (a) (ARB + CR), (b) (ARB + CR + ageing), (c) (ARB + ACR) and (d) (ARB + ACR + ageing). 